\title{
Agro-morphological Study on Induced Mutants and Mutant Hybrids in Lentil (Lens culinaris Medik.)
}

\section{Kumar $\mathbf{S}^{1,2 *}$ and Ramesh $\mathbf{B}^{2}$}

${ }^{1} D D U$ College (University of Delhi), Karampura, New Delhi, India

${ }^{2}$ Department of Genetics and Plant Breeding, C.C.S. University, Meerut, India

\begin{abstract}
Cereals and legumes represent the two most important groups of food crops, so that an improvement in these two groups of crops has been the major concern of plant breeders over the years. In the past, these crops have been improved through several conventional approaches of plant breeding. Mutations provides an opportunity to create hitherto unknown alleles, so that the plant breeder does not remain handicapped due to limited allelic variation at one or more gene loci of interest. A number of mutants have been induced by several workers in lentil by using various physical and chemical mutagens. Present work was undertaken to study the agro-morphological study on induced mutants and mutant hybrids in lentil. Results suggested that of the eight induced mutants studied here, two mutants namely bold seeded and early maturing ones are of economic importance and can be used for direct commercial cultivation, while the rest may be utilized in cross breeding programs.
\end{abstract}

Keywords: Mutation; Breeding; Cereals; Lentil (Lens culinaris Medik.); Hybrids and Mutants

\section{Introduction}

Cereals and legumes represent the two most important groups of food crops, so that an improvement in these two groups of crops has been the major concern of plant breeders over the years. In the past, these crops have been improved through several conventional approaches of plant breeding (including introduction, selection and hybridization) [1]. Mutations provides an opportunity to create hitherto unknown alleles, so that the plant breeder does not remain handicapped due to limited allelic variation at one or more gene loci of interest. A number of mutants have been induced by several workers in lentil by using various physical and chemical mutagens. Many of these mutants need the attention of researchers for detailed studies. Genetic and developmental studies on these mutants would be of immense help for their proper use in crop improvement programmes [2]. India has made significant contributions in the field of mutational studies on pulses leading to the isolation of a number of useful mutants for various characters. However, Studies on various induced morphological and chlorophyll mutants in lentil (cv.T-36) including stunted, curled leaf apex, radicle hypertrophy, bi-lobed cotyledonary leaves, plants with 3 cotyledonary leaves, a barren leaf apex, folded leaflets and giant seedling mutants were carried out by Dixit and Dubey [3,4]. The staggering mutant, on the other hand, has closely arranged long branches, spreading parallel to the ground for most of their length and finally turning upward, decrease in number of branches and pods, leaf and leaflet size, days to flowering, internode length and seed yield. However, practically no information on mutant hybrids is available in lentil. The present study is an attempt in this direction and aimed the agro-morphological study on induced mutants and mutant hybrids in lentil. The information thus obtained will help in better utilization of induced genetic variability in lentil.

\section{Materials and Methods}

\section{Materials}

Eight induced morphological mutants along with their parental controls (P-38 and PL-639) in lentil and their hybrids were used in the present study. All the mutants (listed below) initially were selected from gamma irradiated populations of lentil cultivars P-38 and PL-639 that belong to ssp (Table 1).

Microsperma of Lens culinaris Medik. In M2 and bred true for the altered characters in M3 and subsequent generations. The seed materials for the preset study were kindly provided by Prof. B. Ramesh from the lentil germplasm stocks maintained by him at the Department of Genetics and Plant Breeding, Ch. Charan Singh University campus, Meerut (Table 2).

\section{Methods}

Eight hybrids of induced mutants crossed back to their parental controls along with the mutants and parental controls (P-38 and PL639) were grown in the research farm attached to the department of Genetics and Plant Breeding at Ch. Charan Singh University campus, Meerut. Recommended agronomic and cultural practices for the crop were followed. The materials were grown under identical conditions of irrigation, fertility, climate, etc., to minimize the variation in the growth and development of plants due to these factors. Data on various morphological characters including plant height, stem, leaf, flower, pod and seed characters were recorded at appropriate times. Salient features at a particular stage in different materials were also noted. For recording data on various morphological characters, 10 plants at random for each material were considered and average values were used for making comparisons (Table 3).

${ }^{*}$ Corresponding author: Kumar S, Assistant Professor, Department of Botany, Deen Dayal Upadhyaya College, University of Delhi, Karampura, New Delhi-110015, India, Tel: +91-9810685352; E-mail: sandeep20684@gmail.com

Received January 12, 2016; Accepted February 02, 2016; Published February 08,2016

Citation: Kumar S, Ramesh B (2016) Agro-morphological Study on Induced Mutants and Mutant Hybrids in Lentil (Lens culinaris Medik.). J Food Process Technol 7: 560. doi:10.4172/2157-7110.1000560

Copyright: $\odot 2016$ Kumar S, et al. This is an open-access article distributed under the terms of the Creative Commons Attribution License, which permits unrestricted use, distribution, and reproduction in any medium, provided the original author and source are credited. 
Citation: Kumar S, Ramesh B (2016) Agro-morphological Study on Induced Mutants and Mutant Hybrids in Lentil (Lens culinaris Medik.). J Food Process Technol 7: 560. doi:10.4172/2157-7110.1000560

Page 2 of 6

H.I. $(\%)=\frac{\text { Seed yield per plant }(\mathrm{g}) \times 100}{\text { Biological yield per plant }(\mathrm{g})}$

\section{Results and Discussion}

\begin{tabular}{|c|c|c|}
\hline Controls & Induced mutants & Hybrids \\
\hline \multirow{4}{*}{ P-38 } & Early maturing mutant & Early maturity $\times$ P-38 \\
\cline { 2 - 3 } & Bold seeded mutant & Bold seeded $\times$ P-38 \\
\cline { 2 - 3 } & Very small narrow leaved mutant & Very small narrow leaves $\times$ P-38 \\
\cline { 2 - 3 } & Late maturity mutant & Late maturity $\times$ P-38 \\
\cline { 2 - 3 } & Bushy dwarf mutant & Bushy dwarf $\times$ P-38 \\
\hline \multirow{3}{*}{ PL-639 } & Globe mutant & Globe mutant $\times$ PL-639 \\
\cline { 2 - 3 } & Fasciated mutant & Fasciated $\times$ PL-639 \\
\cline { 2 - 3 } & Stunted mutant & Stunted $\times$ PL-639 \\
\hline
\end{tabular}

Table 1: List of induced mutants, their parental controls and the hybrids used in the present study.
Eight induced morphological mutants of lentil with alterations in plant characters such as plant height (Busy dwarf, Stunted), leaf (Vary small narrow leaves), seed (Bold seeded), maturity (Early maturity and late maturity), stem (Fasciated) and plant architecture (Globe mutant) were crossed with their respective controls. The resulting mutant hybrids along with induced mutants and parental controls were studied and the performance of mutant hybrids was evaluated in relation to corresponding parents. The data on various agronomic traits are presented in Tables 1 (for parental controls and induced mutants) and 2 (for mutant hybrids).

Statistical analysis of data: The data recorded for various characters were statistically analyzed. Mean standard deviation (SD) and standard error (SE) estimates were made by following standard procedures.

\section{Parental controls}

P-38: This control variety has an erect plant type with intermediate, quadrangled, almost glabrous stem and loosely arranged branches with

\begin{tabular}{|c|c|c|}
\hline & Name of the control and mutants & Description of Control and Mutants \\
\hline 1. & P-38 (control) & Erect plant type; long straight loosely arranged branches; light green leaves. \\
\hline 2. & PL-639 (control) & $\begin{array}{l}\text { Erect plant type, long straight loosely arranged branches, light green leaves. This variety (Pant L-639) was the first variety } \\
\text { developed through hybridization from the cross } L 9-12 \times \text { Type } 8 \text { and was released for commercial cultivation in } 1981 \text {. PL- } \\
639 \text { in combination with PL-234 has led to the development of bold seeded variety Lens } 4076 \text {. }\end{array}$ \\
\hline 3. & Early maturity mutant & $\begin{array}{l}\text { This mutant was isolated from gamma irradiated populations of cv. P- } 38 \text {. Erect plant type; branches stouter than control and } \\
\text { loosely arranged; light green leaves; matures } 15 \text { days earlier than control. }\end{array}$ \\
\hline 4. & Late maturing mutant & $\begin{array}{l}\text { This mutant also from cv. P-38 is characterized by erect plant type; long straight loosely arranged branches; light green } \\
\text { leaves but matures } 13 \text { days later than control. }\end{array}$ \\
\hline 5. & Fasciated mutant & $\begin{array}{l}\text { This mutant with alteration in stem development is characterized by flattened stem and also branches giving a band or } \\
\text { ribbon like appearance; numerous floral buds at top region, modification of leaf tip into tendril, also shows early maturity to } \\
\text { its parental control (PL-639). }\end{array}$ \\
\hline 6. & Bushy dwarf mutant & $\begin{array}{l}\text { Easily recognized by its busy plant type with much reduced height and compactly arranged branches, was isolated from cv. } \\
\text { P-38. }\end{array}$ \\
\hline 7. & Bold seeded mutant & $\begin{array}{l}\text { Another mutant of cv. P-38 with erect plant type; long straight loosely arranged branches, light green leaves; large pods, and } \\
\text { bold seeds compared to P-38. }\end{array}$ \\
\hline 8. & Globe mutant & $\begin{array}{l}\text { This mutant with characterized globe appearance was induced in cv. PL-639 through gamma rays treatment. It has erect } \\
\text { plant type, short closely arranged branched, light green leaves, }\end{array}$ \\
\hline 9. & Stunted mutant & $\begin{array}{l}\text { Another reduced height mutant of PL-639 with drastic reduction in plant height, close branches, green closely arranged } \\
\text { leaves }\end{array}$ \\
\hline 10. & Very sma & This mutant is characterized by the alteration in leaflet size along with drastic reduction in plant height. \\
\hline
\end{tabular}

Table 2: A brief description of the different seed materials used in this study.

\begin{tabular}{|c|c|c|}
\hline Characters & Parameters & Mode of Observations \\
\hline Plant height (cm) & Plant height & The height of plant from soil surface to the tip of the extended foliage. \\
\hline \multirow{4}{*}{ Flower characters } & Days to initial bud appearance & Time in days from sowing date to the appearance of first flower bud. \\
\hline & Days to $50 \%$ flowering & Time in days from sowing date to the day when $50 \%$ of the plants have started to flower. \\
\hline & $\begin{array}{l}\text { Number of flowers per } \\
\text { peduncle }\end{array}$ & Maximum number of flowers on a peduncle. \\
\hline & Peduncle length $(\mathrm{cm})$ & The length from base to the tip of peduncle. \\
\hline \multirow{11}{*}{ Pod and seed characters } & Pod pigmentation & Colour of the pods at filling and maturity stages \\
\hline & Pod bearing zone $(\mathrm{cm})$ & The length of the pod bearing portion of the plant at maturity stage. \\
\hline & Height of lower pod (cm) & The height of lower pod from soil level. \\
\hline & Days to maturity & Time in days from sowing to plant maturity. \\
\hline & Pod number/plant & Average number of pods per plant estimated on 10 randomly selected plants. \\
\hline & Seed number/pod & Average value obtained from 15 randomly selected pods per plant. \\
\hline & Size of pod & Length and width of pod at maturity. \\
\hline & Seed yield per plant $(g)$ & The pods of each plant were picked and threshed separately and weight of clean seed was recorded. \\
\hline & Biological yield per plant $(g)$ & Recorded as the dry weight of the whole plant excluding roots at the time of harvesting. \\
\hline & 100 seed weight $(\mathrm{g})$ & Average weight of samples of 100 randomly chosen seeds. \\
\hline & Harvest index (H. I.) & Calculated on the basis of the following formula: \\
\hline
\end{tabular}

Table 3: The various parameters that were considered in the present study. 
narrow angles. The leaves are alternate, pinnate, stipulate and petiolate with short petioles. Leaves are usually light green in colour except for the appearance of purple pigment at leaf base at the beginning of leaf development which later turns into green. Flowers are borne on an axillary raceme inflorescence with a slender peduncle. The rachis of the inflorescence ends in a filiform apex with no bracts and the pedicels are short. Each peduncle normally bears two to three flowers. Flowers are small in size and the standard petal is white coloured with light purplish blue veins. The pods are oblong and laterally compressed. This control with a plant height of $\sim 32 \mathrm{~cm}$ recorded the initial bud appearance at 92 days after sowing while for $50 \%$ flowering and maturity, it took 113 days and 142 days, respectively after sowing. There were a total 120 pods per plant and the grain yield and biological yield were recorded as $2.83 \mathrm{~g}$ and $8.36 \mathrm{~g}$, respectively with a 100 seeds weight of $1.83 \mathrm{~g}$ while harvest index was $33.85 \%$ (Table 4 ).

PL-639: This is another control variety with erect plant type and has intermediate, quadrangled, almost glabrous stem and loosely arranged branches with narrow angles. Leaves are alternate, pinnate, stipulate and petiolate with short petioles and are usually light green in colour except for the appearance of purple pigment at the base at the beginning of leaf development. Flowers are borne on an axillary raceme inflorescence with a slender peduncle. Each peduncle normally bears two to three small flowers. The standard petal of the flower is white in colour with light purplish blue veins. The pods are oblong and laterally compressed. This is slightly taller $(\sim 34 \mathrm{~cm})$ than cv. P.38 and takes 147 days for maturity. In agronomic traits, it is comparable to P-38 (Table 4).

\section{Induced mutants}

Early maturity mutant: It was characterized by its earliness in flowering, pod setting and plant maturity. This matured 14 days earlier than its parental control (P-38). The mutant has also an erect plant type with thin, quadrangled, almost glabrous stem and loosely arranged branches with narrow angles, leaves are usually light green in colour, each peduncle normally bears 3 flowers, but in some cases 4 flowers were present. It exhibited an improvement in plant height $(35 \mathrm{~cm})$ and number of pods/ plant (125) as compared to control. The plant grain yield (3.28 g) and biological yield (10.91 g) were also improved over control though the 100 seeds weight and harvest index recorded a decrease (Table 4). Early maturity mutant with a marked decrease in flowering and maturity periods recorded increase of grain yield, mainly due to increased number of pods per plant and higher seed weight. It seems that this mutant has probably greater number of growth points than the control. Therefore, it offers two advantages over the existing plant types: (1) Use of higher seed rate, possibly leading to a higher yield per unit area, (2) Early maturity is highly recommended for late sowing condition. Early maturing mutants have been isolated by several workers earlier in lentil [5] and their results were almost similar to the results of the present study. Duration of maturity period is generally controlled by many genes; therefore, a greater number of genotypes can be expected in mutation treatments differing from each other for this character. A large number of early flowering and/or ripening mutants have been selected in many crops following treatment with different physical and chemical mutagens. Kaul [6] and Singh [7] in pea, Dixit and Dubey [2] and Kalia and Gupta [8] in lentil isolated early maturing and high yielding mutants.

Bold seeded mutant: It showed conspicuous improvement in several plant traits including yield, plant height, number of leaves, pod size, leaflet size and harvest index compared to its control (P-38). The mutant with large and bold seeds also matured one week earlier to control (Table 4). In the bold seeded mutant, seed size and/or shape have been altered. Bold seeded mutant with large and bold seeds had exhibited increase in a number of agronomic traits including plant height, leaflet size, length of pod bearing zone, seed weight, grain yield and biological yields. The increase in grain yield and biological yield was due to increased size of leaflets (resulting in increased photosynthesis) and higher seed weight (because of increased seed size). It seems that the bold seeded mutant has probably greater number of growth points than the control.

Bushy dwarf mutant: This mutant of P-38 is characterized by its branches being compactly arranged to give it a characteristic bushy shape and resistant to lodging as there was considerable reduction in plant height (by $8 \mathrm{~cm}$ ) as compared to control. It also exhibited reduction in a number of agronomic traits, thereby giving lower grain yield and biological yield. Further, the mutant exhibited lateness in flowering and maturity (Table 4). Bushy dwarf belongs to the category of reduced plant height mutants, one of the most frequently arising types in mutation experiments [9]. Bushy dwarf mutant having dense growth with compactly arranged branches, on the other hand, exhibited reductions in a number of agronomic and yield characters thereby giving lower grain yield. Further, it also showed lateness in flowering and maturity. Bushy dwarf mutant types have been reported by several workers earlier not only in lentil $[5,10,11]$, but also in other crops like Vigna. A bushy mutant of Vigna trilobata with a high number of branches was found to have a considerably better seed yield per plant than the control [9]. This holds true for a pyramid shaped genotype of Vigna aconitifolia [12]. Morphological mutations having reduced plant height offer an interesting study. Irrespective of the basis of reduction in plant height, most of these mutations have two advantages: (1) Due to compactness, they cover very little space, therefore, by increasing seed rate, they will give higher yield per unit area; and (2) Resistance to lodging, though this is not a serious problem in lentils [13].

Very small narrow leaved mutant: In this mutant of P-38 both the length and width of leaflets are markedly reduced. The plant height $(16.76 \mathrm{~cm})$ was also much reduced as compared to control. The leaflets on the rachis appear to be sparsely arranged because of reduced width of the leaflets. Each peduncle normally bears 2-3 flowers. The mutant showed earliness (by 10 days) in flowering and maturity over the control. The yield traits were markedly reduced in this mutant, thereby exhibiting drastically reduced values for number of pods (only 18/ plant) and grain and biological yields, 100 seeds weight and harvest index (Table 4). Very small narrow leaved mutant, belonging to the leaf mutant's category, exhibited marked changes in the leaflet size and shape. There was reduction in length as well as width of the leaflet in this mutant, although the extent of reduction was much in the latter (width) compared to the former (length). Very small narrow leaves mutant characterized by the alteration in leaflet size was accompanied with drastic reduction in the plant height. The reduced leaflet size was responsible for the low number of pods formed and thereby, reduced grain yield as there was drastic reduction in the photosynthetic area (Total leaf area) and thus affecting the photosynthesis. Mutations affecting dimentions of leaves and leaflets have earlier been recorded in lentil genotypes of both microsperma and macrosperma groups [2,14] In narrow leaflets mutants, Dixit and Dubey [2] observed that the length of the leaflets was normal or in a few cases, slightly increased, but the width of the leaflets was very much reduced and because of this, the leaflets appeared to be sparsely arranged. In small and narrow leaflets mutants, they [3] observed that both the length and width of leaflets were markedly reduced. The length of rachis was also reduced. The leaflets of one of these mutants were rudimentary. These observations were similar to the results of the present investigation. 
Late maturity mutant: This mutant is characterized by lateness (by 14-18 days) in flowering, pod setting and maturity of the plants over its parental control (P-38). However, the mutant showed significant increase in a number of agronomic traits including number of pods, grain yield, biological yield, 100 seeds weight and harvest index (Table 4).

Globe mutant: This mutant (of PL-639) has markedly reduced plant height $(23.60 \mathrm{~cm})$ compared to its control. The mutant has an erect plant type with glabrous stem, compactly arranged branches giving a characteristic globe appearance. The flowering and maturity occurred 3 days earlier than the control. The plant grain and biological yields recorded a marked decrease mainly due to reduced number of pods and 100 seed wt. though there was significant increase in harvest index $(36.77 \%)$ over its control (Table 4$)$.

Fasciated mutant: In this mutant, the upper part of the main stem and sometimes even branches are modified into broadened bandlike structure. This anomaly is often associated with the formation of numerous floral buds and also more flowers at the top region. However, only a small proportion of these flowers transform into pods. The tip of rachis in the upper part of the stem has developed into a tendril. Accumulation of tendrils at the top region of the stem has occurred due to the shortening of the apical internodes. Leaflets size is medium to long and broader compared to its control. Other feature associated with fasciation is reduction in seed size. It exhibited improvement in plant height and maturity (early maturing by 11 days) but there was significant reduction in number of pods, plant grain yield and biological yield (Table 4). Fasciated mutant is characterized by the presence of fasciation of stem and upper branches. This anomaly is associated with accumulation of a large number of floral buds in the top region of the plants. Another important feature in this mutant is the modification of the apex of rachis (leaf) in to a tendril and the accumulation of the tendrils in the top region of the stem due to shortening of the apical internodes. Genetically conditioned stem fasciation is wide spread in higher plants. The fasciated mutants have both favorable and unfavorable characters. Among cultivated plants, fasciated genotypes are of some importance for breeding purposes. The number of pods per plant is lower than in control, resulting in decreased seed production. The accumulation of tendrils in the top region of the stem and increase in the number of foliage leaves as a consequence of fasciation on the other hand lead to high amount of lodging resistance. In lentil, two fasciated mutants namely fasciata-1 and fasciata-2, isolated by Sharma and Sharma [15] were found to be sterile and hence, are of no economic value. However, the fasciated mutants isolated by Dixit and Dubey [6] and Singh [7] were fully fertile and recorded higher yields than the control. The fasciated mutant of the present study was shorter than the control and also associated with earliness.

Stunted mutant: It has semi-erect plant type with markedly reduced plant height $(8.46 \mathrm{~cm}$ only). Leaves are alternate, compactly arranged and glabrous stem. The mutant exhibited lateness in flowering, pod setting and plant maturity as compared to control. The number of pods/plant was much reduced (28) compared to control. The grain yield and biological yield were also reduced, but the seed size is large and 100 seeds weight was much improved (Table 4). In globe and stunted mutants, late maturity was associated with reduced plant height. The reduction in plant height can be due to either reduction in the number of internodes or in the length of internodes arising due to reduction in cell length of cell number [16]. The stunted mutant has been accompanied with reduction in a number of other traits like pods, seed yield, etc. Similar observation was made earlier by Narahari [17] in rice.

\section{Mutant hybrids}

Early maturity x P-38: This mutant hybrid exhibited earliness in days to flowering, pod formation and plant maturity with reduced plant height compared to early maturity mutant. Further, it exhibited improvement in grain and biological yields over both the parents with increase in pod number though there was decrease in pod bearing zone. This mutant hybrid with higher yield and reduced height and earliness is much better than early maturity mutant and parental control, P-38 (Table 5).

Bold seeded x P38: Bold seeded mutant was better yielding with large, bold seeds and increased seed size and weight over its parental control (P-38) (Table 3). In the mutant hybrid, there was further improvement in grain yield with an increase in pod number. Further, there was marked reduction in plant height, especially in comparison to bold seeded mutant, which was much taller to its parental control. Therefore, mutant hybrid has more desirable agronomic traits over that of bold seeded mutant and also P-38 control (Table 5).

Bushy dwarf $x$ P-38: The bushy dwarf mutant is inferior to its parental control (P-38) in several agronomic traits including grain yield (Table 3 ) and therefore, has no direct commercial value. However, its hybrid with P-38 recorded a marked improvement in most of the agronomic traits including grain and biological yields with increased number of pods, and higher harvest index coupled with marked reduction in days to flowering and maturity (Table 4). This serves as an example of utility of agronomically inferior mutants in cross breeding programs.

Very small narrow leaves $\mathbf{x}$ P-38: The VSNL mutant with characteristic small, narrow leaves was agronomically very poor with very low grain yield though it is early maturing over its parental control (P-38) (Table 4). However, when this induced mutant is crossed with P-38 and the resulting mutant hybrid exhibited a significant improvement in grain and biological yields, harvest index and plant height (Table 5) and can be considered as a better replacement to P-38.

Late maturity $\mathbf{x}$ P-38: The late maturity mutant was better yielding than P-38 (control) though it was late in flowering and maturity periods (Table 4). The mutant hybrid, on the other hand, exhibited earliness in flowering, pod formation and plant maturity, at the same time retaining (or even improving) the higher grain and biological yields (Table 5). This mutant hybrid with better yield performance definitely signifies the use of induced mutants in recombination breeding for development of superior, high yielding mutant cultivars in lentil.

Globe $x$ PL-639: The induced mutant was a semi-dwarf with markedly reduced yield in comparison to its parental control (PL-639) (Table 4). However, when it is crossed back to its parental control, the resulting mutant hybrid showed marked improvements in plant height, number of pods, grain yield, biological yield and harvest index (Table 5). The mutant hybrid is much better to PL-639 in yield and several yield components.

Fasciated x PL-639: The fascinated mutant was a poor yielder in comparison to its parental control (PL-639) though it was early maturing (Table 4). The mutant hybrid (Fasciated x PL-639), on the other hand, exhibited significant improvement in grain yield with marked increase in number of pods, at the same time retained its early maturing (Table 5)

Stunted x PL-639: The stunted mutant with drastic reduction in plant height, grain yield and several other agronomic traits cannot be 


\begin{tabular}{|c|c|c|c|c|c|c|c|c|c|c|c|c|c|c|c|c|c|c|c|c|c|c|c|c|}
\hline 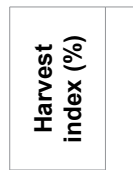 & $\begin{array}{l}\mathcal{N} \\
\stackrel{7}{.} \\
+1 \\
\stackrel{+}{0} \\
\infty \\
\tilde{e}\end{array}$ & 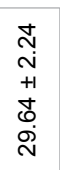 & & \begin{tabular}{l}
\multirow{1}{c}{} \\
$\dot{+}$ \\
+1 \\
0 \\
0 \\
$\dot{m}$
\end{tabular} & 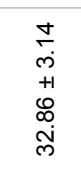 & 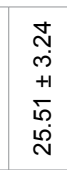 & $\begin{array}{l}\bar{\delta} \\
\stackrel{+}{+1} \\
+1 \\
\stackrel{\infty}{+} \\
\bar{m}\end{array}$ & $\begin{array}{l}\infty \\
\stackrel{\infty}{0} \\
+1 \\
+1 \\
\infty \\
\infty \\
\dot{m}\end{array}$ & & $\begin{array}{l}\hat{n} \\
+ \\
+1 \\
+ \\
\hat{D} \\
\dot{0}\end{array}$ & \begin{tabular}{l}
\multirow{T}{c}{} \\
+1 \\
$0+$ \\
0 \\
$i$ \\
$N$
\end{tabular} & $\begin{array}{l}\stackrel{O}{+} \\
+1 \\
+1 \\
m \\
\check{m} \\
\dot{m}\end{array}$ & & 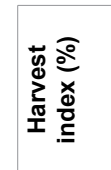 & & $\begin{array}{l}\hat{f} \\
\dot{0} \\
+1 \\
0 \\
0 \\
\dot{0}\end{array}$ & 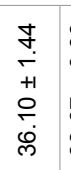 & $\begin{array}{l}8 \\
\dot{0} \\
0 \\
+1 \\
+ \\
0 \\
0 \\
0 \\
0\end{array}$ & 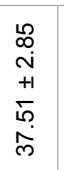 & 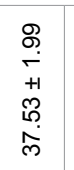 & 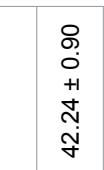 & $\begin{array}{l}\infty \\
\infty \\
0 \\
+1 \\
0 \\
e \\
e\end{array}$ & $\begin{array}{l}\text { N } \\
\text { + } \\
+1 \\
+1 \\
+ \\
\dot{m}\end{array}$ & \\
\hline 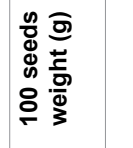 & $\begin{array}{l}\stackrel{0}{0} \\
0 \\
+1 \\
\infty \\
\infty \\
\stackrel{+}{+}\end{array}$ & $\begin{array}{l}\tilde{0} \\
0 \\
+1 \\
\infty \\
\stackrel{1}{\leftarrow} \\
\stackrel{-}{r}\end{array}$ & & $\begin{array}{l}8 \\
0 \\
0 \\
+1 \\
\stackrel{1}{R} \\
\stackrel{1}{\leftarrow}\end{array}$ & 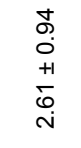 & $\begin{array}{l}\bar{\delta} \\
0 \\
+1 \\
+1 \\
o \\
\dot{0}\end{array}$ & $\begin{array}{l}8 \\
0 \\
+1 \\
+1 \\
\stackrel{+}{+}\end{array}$ & 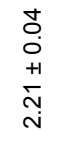 & & $\begin{array}{l}\dot{0} \\
\dot{0} \\
++1 \\
\dot{0} \\
\dot{+}\end{array}$ & 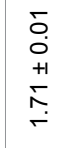 & 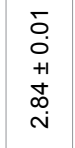 & & 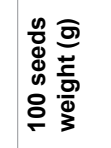 & & 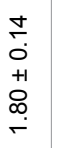 & $\begin{array}{l}0 \\
\infty \\
0 \\
+1 \\
\stackrel{+}{0} \\
\stackrel{N}{1}\end{array}$ & 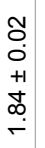 & $\begin{array}{l}8 \\
0 \\
0 \\
+1 \\
\dot{0} \\
\dot{r}\end{array}$ & 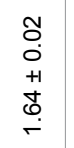 & 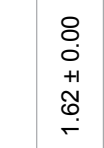 & $\begin{array}{l}\bar{c} \\
\dot{0} \\
+1 \\
+ \\
\stackrel{1}{r} \\
\end{array}$ & $\begin{array}{l}\infty \\
0 \\
0 \\
+1 \\
\infty \\
i \\
i\end{array}$ & \\
\hline 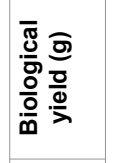 & \begin{tabular}{l}
\multirow{N}{0}{} \\
0 \\
+1 \\
0 \\
$\infty$ \\
$\infty$
\end{tabular} & $\begin{array}{l}\hat{D} \\
0 \\
+1 \\
+1 \\
\infty \\
\infty \\
0\end{array}$ & & $\begin{array}{l}5 \\
\dot{5} \\
+1 \\
+1 \\
\dot{0} \\
\dot{0}\end{array}$ & $\begin{array}{l}\stackrel{8}{\circ} \\
\stackrel{+}{+1} \\
\infty \\
\infty \\
\infty \\
\infty\end{array}$ & \begin{tabular}{l}
\multirow{2}{0}{} \\
+ \\
++1 \\
$+\infty$ \\
$\stackrel{+}{+}$
\end{tabular} & $\begin{array}{l}0 \\
0 \\
0 \\
+1 \\
\hat{\sigma} \\
j\end{array}$ & 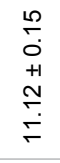 & & $\begin{array}{l}0 \\
0 \\
0 \\
+1 \\
0 \\
0 \\
0\end{array}$ & $\begin{array}{l}\stackrel{8}{0} \\
0 \\
0 \\
+1 \\
i \\
0\end{array}$ & $\begin{array}{l}\widetilde{N} \\
0 \\
0 \\
+1 \\
\stackrel{N}{N} \\
\text { }\end{array}$ & & 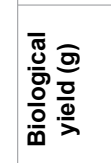 & & $\begin{array}{l}\infty \\
0 \\
0 \\
+1 \\
0 \\
0 \\
\stackrel{+}{+}\end{array}$ & $\begin{array}{l}0 \\
0 \\
0 \\
+1 \\
0 \\
0 \\
0 \\
0\end{array}$ & 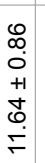 & 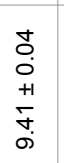 & $\begin{array}{l}\infty \\
0 \\
0 \\
+1 \\
0 \\
0 \\
0 \\
0\end{array}$ & $\begin{array}{l}\infty \\
\infty \\
0 \\
+1 \\
+\vdots \\
+ \\
0\end{array}$ & $\begin{array}{l}\hat{E} \\
\dot{0} \\
+1 \\
0 \\
0 \\
0\end{array}$ & 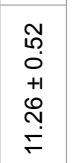 & \\
\hline 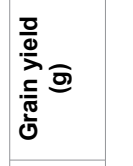 & $\begin{array}{l}\stackrel{N}{\infty} \\
0 \\
+1 \\
\infty \\
\stackrel{N}{N}\end{array}$ & $\begin{array}{l}\infty \\
\stackrel{\infty}{0} \\
\stackrel{+1}{N} \\
\stackrel{N}{i}\end{array}$ & & 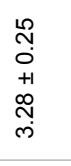 & $\begin{array}{l}\ddot{0} \\
0 \\
0 \\
+1 \\
0 \\
0 \\
\dot{m}\end{array}$ & 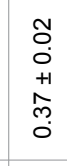 & $\begin{array}{l}\infty \\
\stackrel{\infty}{0} \\
0 \\
+1 \\
\stackrel{1}{0} \\
\stackrel{\leftrightarrow}{+} \\
\end{array}$ & $\begin{array}{l}\stackrel{D}{N} \\
0 \\
+1 \\
+\infty \\
\infty \\
0 \\
0\end{array}$ & & $\begin{array}{l}\circ \\
0 \\
++1 \\
\infty \\
\infty \\
i \\
i\end{array}$ & 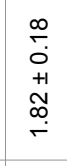 & $\begin{array}{l}5 \\
0 \\
0 \\
+1 \\
8 \\
0 \\
0\end{array}$ & & 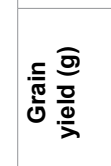 & & $\begin{array}{l}\text { शे } \\
\text { o } \\
+1 \\
0 \\
0 \\
\end{array}$ & $\begin{array}{l}\infty \\
\infty \\
0 \\
+1 \\
+1 \\
0 \\
0 \\
0\end{array}$ & 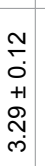 & 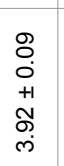 & $\begin{array}{l}\tilde{N} \\
0 \\
0 \\
+1 \\
0 \\
\dot{j} \\
\dot{x}\end{array}$ & 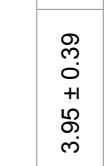 & 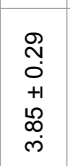 & 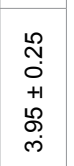 & \\
\hline 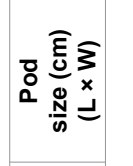 & $\begin{array}{l}0 \\
0 \\
0 \\
x \\
\circ \\
\circ \\
0\end{array}$ & $\begin{array}{l}0 \\
0 \\
0 \\
x \\
0 \\
\stackrel{0}{r}\end{array}$ & & $\begin{array}{l}\text { No } \\
0 \\
0 \\
x \\
8 \\
\stackrel{+}{r}\end{array}$ & 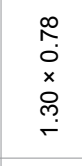 & $\begin{array}{l}\tilde{N} \\
0 \\
0 \\
x \\
0 \\
0 \\
0\end{array}$ & \begin{tabular}{l}
$\infty$ \\
\multirow{0}{0}{} \\
0 \\
$x$ \\
$\hat{0}$ \\
0 \\
0
\end{tabular} & \begin{tabular}{l}
$\infty$ \\
\multirow{0}{0}{} \\
$x$ \\
$x$ \\
$\hat{o}$ \\
0 \\
0
\end{tabular} & & $\begin{array}{l}0 \\
0 \\
0 \\
x \\
x \\
\infty \\
\infty \\
0 \\
0\end{array}$ & 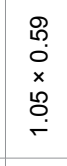 & $\begin{array}{l}0 \\
\stackrel{0}{0} \\
0 \\
\times \\
8 \\
\stackrel{0}{r}\end{array}$ & 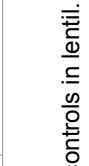 & 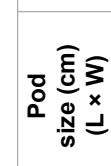 & & 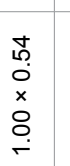 & 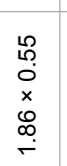 & 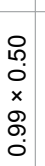 & $\begin{array}{l}0 \\
0 \\
0 \\
x \\
x \\
0 \\
0 \\
0 \\
0\end{array}$ & $\begin{array}{l}0 \\
0 \\
0 \\
x \\
0 \\
0 \\
\dot{x}\end{array}$ & $\begin{array}{l}0 \\
0 \\
0 \\
x \\
x \\
\infty \\
\infty \\
0 \\
0\end{array}$ & $\begin{array}{l}\text { vo } \\
0 \\
0 \\
x \\
0 \\
0 \\
0 \\
0\end{array}$ & 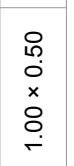 & \\
\hline 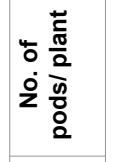 & $\begin{array}{l}\text { ț } \\
0 \\
+1 \\
\stackrel{+}{\sim}\end{array}$ & 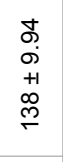 & & 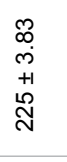 & $\begin{array}{l}\infty \\
\stackrel{\infty}{1} \\
\text { +1 } \\
+1 \\
\infty\end{array}$ & $\begin{array}{l}\stackrel{\sim}{\sim} \\
\stackrel{+}{+1} \\
\stackrel{\infty}{\leftarrow}\end{array}$ & $\begin{array}{l}0 \\
\stackrel{\infty}{\infty} \\
+1 \\
\infty \\
\infty\end{array}$ & $\begin{array}{l}\bar{m} \\
\dot{0} \\
+1 \\
\stackrel{+}{\sim}\end{array}$ & & $\begin{array}{l}\bar{m} \\
\stackrel{+}{+} \\
+1 \\
\stackrel{N}{\sim}\end{array}$ & 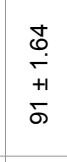 & $\begin{array}{l}\hat{N} \\
+ \\
+1 \\
\infty \\
\stackrel{N}{N}\end{array}$ & 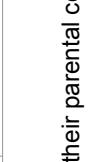 & 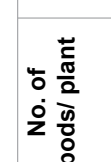 & & 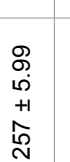 & $\begin{array}{l}\infty \\
\infty \\
\infty \\
+1 \\
+1 \\
\stackrel{\Gamma}{r}\end{array}$ & 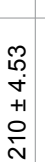 & 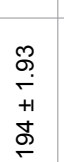 & $\begin{array}{l}\hat{f} \\
\stackrel{+}{+} \\
+1 \\
\stackrel{D}{\sigma}\end{array}$ & 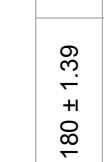 & 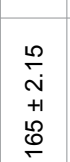 & 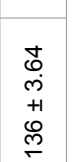 & \\
\hline 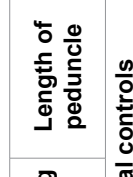 & $\begin{array}{l}\infty \\
\stackrel{0}{0} \\
+1 \\
\stackrel{N}{N} \\
\text { N }\end{array}$ & $\begin{array}{l}\circ \\
0 \\
+1 \\
+\infty \\
\stackrel{\omega}{1}\end{array}$ & 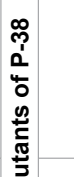 & $\begin{array}{l}\circ \\
0 \\
0 \\
+1 \\
\infty \\
i \\
i\end{array}$ & $\begin{array}{l}\stackrel{m}{0} \\
\stackrel{+}{+1} \\
\stackrel{+}{m} \\
\stackrel{N}{j}\end{array}$ & $\begin{array}{l}m \\
\stackrel{m}{0} \\
++1 \\
+1 \\
+ \\
\stackrel{+}{+}\end{array}$ & 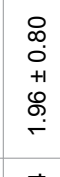 & $\begin{array}{l}\hat{o} \\
0 \\
+1 \\
o \\
o \\
0 \\
0\end{array}$ & 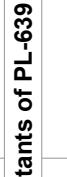 & $\begin{array}{l}\tilde{J} \\
0 \\
++1 \\
\infty \\
\infty \\
+\end{array}$ & $\begin{array}{l}0 \\
0 \\
0 \\
+1 \\
\stackrel{8}{i} \\
i\end{array}$ & $\begin{array}{l}0 \\
0 \\
0 \\
+1 \\
0 \\
0 \\
0\end{array}$ & 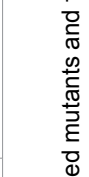 & 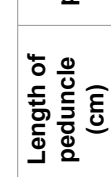 & $\begin{array}{l}\infty \\
0 \\
0 \\
0 \\
0 \\
0 \\
0\end{array}$ & 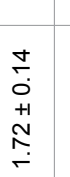 & 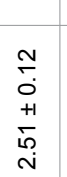 & 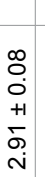 & 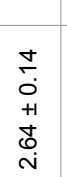 & $\begin{array}{l}8 \\
0 \\
0 \\
+1 \\
0 \\
\stackrel{+}{+}\end{array}$ & 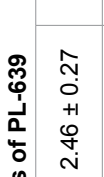 & $\begin{array}{l}\stackrel{N}{c} \\
\dot{0} \\
+1 \\
\stackrel{N}{N}\end{array}$ & 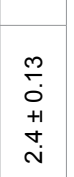 & \\
\hline 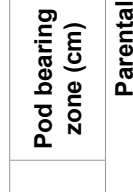 & 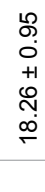 & 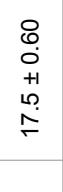 & 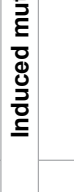 & $\begin{array}{l}\infty \\
\stackrel{+}{+} \\
\stackrel{+1}{N} \\
\stackrel{N}{+}\end{array}$ & 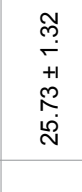 & $\begin{array}{l}\overline{0} \\
0 \\
+1 \\
0 \\
0 \\
0\end{array}$ & 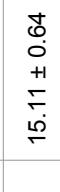 & $\begin{array}{l}0 \\
0 \\
0 \\
+1 \\
\infty \\
0 \\
\infty \\
\infty\end{array}$ & 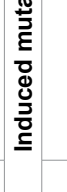 & $\begin{array}{l}5 \\
\dot{+} \\
+1 \\
0 \\
0 \\
0\end{array}$ & 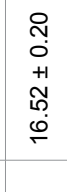 & $\begin{array}{l}\hat{\sim} \\
\dot{0} \\
+1 \\
\stackrel{\leftrightarrow}{N} \\
\dot{\sigma}\end{array}$ & 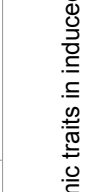 & 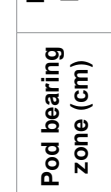 & 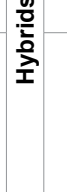 & 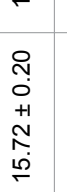 & $\begin{array}{l}1 \\
0 \\
f \\
0 \\
+1 \\
0 \\
0 \\
0 \\
0\end{array}$ & 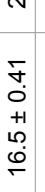 & 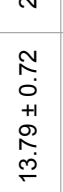 & 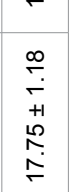 & 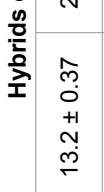 & \begin{tabular}{l}
0 \\
\multirow{2}{0}{} \\
+1 \\
+1 \\
$\infty$ \\
$\infty$ \\
$\stackrel{0}{0}$
\end{tabular} & 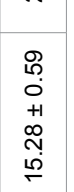 & \\
\hline 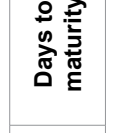 & $\stackrel{\mathcal{F}}{\leftarrow}$ & $\stackrel{\tilde{J}}{\sigma}$ & & $\stackrel{\infty}{\sim}$ & $\stackrel{\mathscr{m}}{=}$ & $\stackrel{\text { ల్ }}{=}$ & 吕 & $\stackrel{\circ}{\circ}$ & & $\underset{\leftarrow}{g}$ & 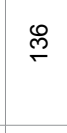 & 号 & $\bar{\Phi}$ & 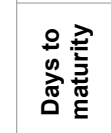 & & $\stackrel{\mathscr{N}}{\stackrel{N}{2}}$ & $\begin{array}{l}\mathscr{0} \\
\stackrel{m}{\longrightarrow}\end{array}$ & 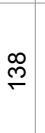 & $\stackrel{g}{g}$ & $\underset{\square}{\check{\sigma}}$ & $\stackrel{g}{g}$ & 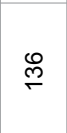 & 吕 & \\
\hline 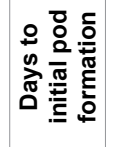 & $\stackrel{m}{ }$ & $\stackrel{\vec{t}}{\rightleftharpoons}$ & & ஜ & $\stackrel{\infty}{\circ}$ & 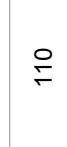 & $\stackrel{\infty}{\rightleftharpoons}$ & 욤 & & $\stackrel{ }{ }$ & 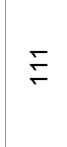 & $\stackrel{?}{\leftarrow}$ & $\dot{\stackrel{\dot{\theta}}{*}}$ & 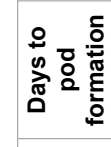 & & 8 & \& & œ & $\stackrel{\infty}{\wedge}$ & $\infty$ & 8 & $\tilde{\sigma}$ & హ゙ & \\
\hline 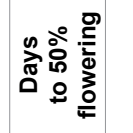 & $\stackrel{\leftrightarrow}{\circ}$ & 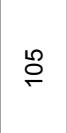 & & $\infty_{\infty}^{\infty}$ & $\stackrel{0}{\circ}$ & む) & $\stackrel{\circ}{\square}$ & $\stackrel{\infty}{\rightleftharpoons}$ & & $\stackrel{\text { d }}{\stackrel{2}{2}}$ & $\stackrel{\Sigma}{\circ}$ & $\stackrel{ }{\circ}$ & $\frac{0}{\frac{0}{\pi}}$ & 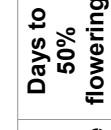 & & 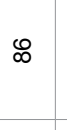 & 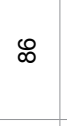 & $\infty$ & $\hat{0}$ & N & б. & $\mathscr{\infty}$ & $\infty$ & $\stackrel{\infty}{\infty}$ \\
\hline 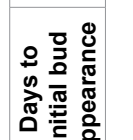 & $\delta$ & ळ & & R & $œ$ & $\infty$ & ஜ & $\stackrel{8}{\circ}$ & & ৪ & ৪ & б. & 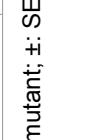 & 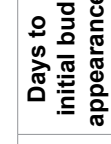 & & & న & న & $\widetilde{\sigma}$ & 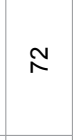 & $\stackrel{\infty}{\infty}$ & $\stackrel{\mathscr{R}}{\curvearrowright}$ & N & 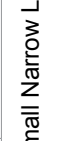 \\
\hline 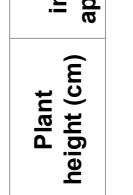 & $\begin{array}{l}\infty \\
\infty \\
0 \\
+1 \\
\stackrel{\infty}{N} \\
\end{array}$ & 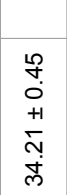 & & 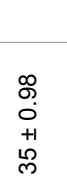 & 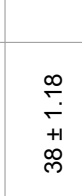 & $\begin{array}{l}\hat{0} \\
0 \\
+1 \\
0 \\
0 \\
0 \\
0\end{array}$ & 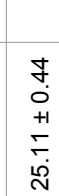 & $\begin{array}{l}\mathbf{c} \\
0 \\
0 \\
+1 \\
0 \\
0 \\
0 \\
0\end{array}$ & & 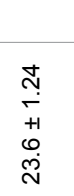 & 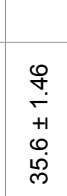 & 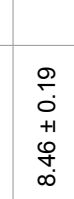 & 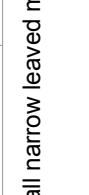 & 蒙 & & $\begin{array}{l}\stackrel{2}{0} \\
\dot{+} \\
+1 \\
0 \\
\dot{m} \\
\dot{m}\end{array}$ & 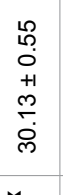 & 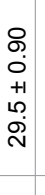 & $\begin{array}{l}0 \\
\stackrel{1}{0} \\
0 \\
+1 \\
⿱ \\
\stackrel{N}{+} \\
\stackrel{N}{+}\end{array}$ & $\begin{array}{l}\stackrel{0}{m} \\
\stackrel{+}{+1} \\
m \\
\stackrel{m}{\dot{m}}\end{array}$ & $\begin{array}{l}\infty \\
0 \\
0 \\
+1 \\
+1 \\
\stackrel{0}{\infty} \\
\stackrel{\infty}{\infty}\end{array}$ & 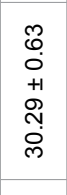 & $\begin{array}{l}\stackrel{\infty}{c} \\
\dot{+} \\
+1 \\
0 \\
\infty \\
\sim \\
\sim\end{array}$ & 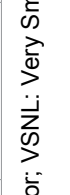 \\
\hline 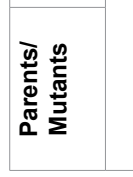 & 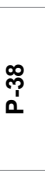 & 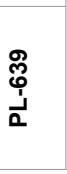 & $\begin{array}{l}\text { 골 } \\
\text { ய. }\end{array}$ & נै & $\begin{array}{l}\text { 형 } \frac{\delta}{\delta} \\
\infty \\
\Phi\end{array}$ & $\overline{\mathbf{z}}_{\mathbf{9}}$ & 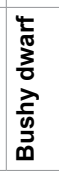 & 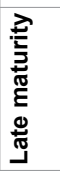 & & 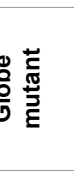 & 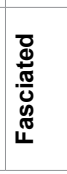 & 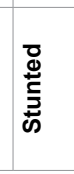 & 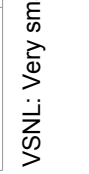 & 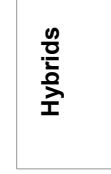 & & 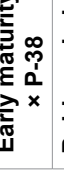 & 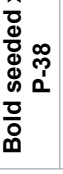 & & 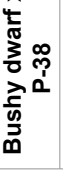 & 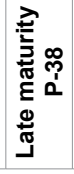 & 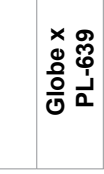 & 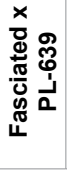 & 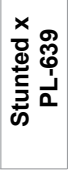 & 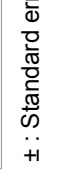 \\
\hline
\end{tabular}


Citation: Kumar S, Ramesh B (2016) Agro-morphological Study on Induced Mutants and Mutant Hybrids in Lentil (Lens culinaris Medik.). J Food Process Technol 7: 560. doi:10.4172/2157-7110.1000560

Page 6 of 6

considered in terms of its commercial use. But its hybrid (Stunted $\mathrm{x}$ PL-639) exhibited significant improvement in several agronomic traits thereby marked increase in grain yield. Further, the mutant hybrid showed earliness in flowering, pod setting and plant maturity. In most of the mutants studied, the shoot system was altered in one way or other resulting in increase or decrease in plant height, number of primary branches and leaves, etc. Very large proportion of genes of the genome of higher plant controls the organization of the shoot system. This becomes obvious from the large number of mutants with alteration in this plant organ arising in mutation treatments.

\section{Conclusion}

Of the eight induced mutants studied here, two mutants namely bold seeded and early maturing ones are of economic importance and can be used for direct commercial cultivation, while the rest may be utilized in cross breeding programs. Though most of the induced mutants studied here are not of commercial importance because of their poor grain yield, but these same mutants when employed in cross breeding experiments with their parental controls, and the resulting mutant hybrids performed much better than the mutants and also controls. Almost all the eight mutant hybrids exhibited markedly higher grain yield and biological yields with significant improvements in several agronomic traits. The results of the present study clearly endorse the better utility of induced mutants (with low grain yield) in hybridization programs for development of high yielding mutant hybrids.

\section{References}

1. Ahloowalia BS, Maluszynski M, Nichtein K (2004) Global impact of mutationderived varieties. Euphytica 135: 187-204.

2. Dixit $P$, Dubey DK (1984) Frequency and spectrum of mutations induced by chemical mutagens in lentil (Lens culinaris Medik.) var. T 36. Life Sci Adv 3: 159-163.

3. Dixit P, Dubey DK (1983) Induced mutations in lentil (Lens culinaris Med.). LENS Newsletter 10: 7-10.
4. Dixit P, Dubey DK (1986) Three interesting mutants in Lentil. LENS Newsletter 13: 5-7.

5. Vandana AT, Dubey DK (1994) Frequency and spectrum of mutations induced by ethylmethane sulphonate (EMS) and diethyl sulfate (DES) in lentil var. K-85. LENS Newsletter 21: 16-19.

6. Kaul AK (1989) Research on combining nutritive quality with high yield, Recent Research on the Improvement of Protein and Nutritive Properties of Food and Feed Plants. IARI Res Ser 6: 7-32.

7. Singh O (1988) Induced mutations and cytogenetic studies in chickpea (Cicer arietinum L.). Meerut University, Meerut.

8. Kalia NR, Gupta VP (1989) Induced polygenic variation in lentils. LENS Newsletter 16: 8-16.

9. Gottschalk W, Wolff G (1983) Induced Mutations in Plant Breeding. Springerverlag, Berlin.

10. Tyagi BS, Gupta PK (1991) Induced mutations for fasciation in lentil (Lens culinaris Med.). Indian Jour Genet 51: 326-331.

11. Tripathi A, Dubey DK (1992) Frequency and spectrum of mutations induced by separate and simultaneous application of gamma rays and ethylmethane sulphonate (EMS) in two microsperma varieties of lentil. LENS Newsletter 19: 3-7.

12. Subramaniam DC (1980) Effect of gamma radiation in Vigna. Indian Jour Genet 40: 187-194.

13. Ramesh B, Dhananjay S (1996) Developmental morphology of induced semidwarf and stunted mutants in lentil. Indian Jour Genet 56: 335-340.

14. Sharma SK, Sharma B (1984) Pattern of induced macro and micromutations with gamma rays and NMU in lentil. Environ Exp Bot 24: 343-351.

15. Sharma SK, Sharma B (1979) Leaf mutations with NMU and gamma rays in lentil (Lens culinaris Medik.). Curr Sci 48: 917-919.

16. Weber E, Gottschalk W (1973) Die Benichungen zwischan zellgrobeund internodien large beistrableninduzierten Pisum Mutanten. Beitr Biol Pfl 49: 101-126.

17. Narahari $P$ (1969) X-ray induced mutant in indica rice variety. Proc Symp "Radiations and Radiomimetic Substances in Mutation Breeding", DAE Bombay. 